\title{
Rethinking Transforming Communications: An Introduction
}

\author{
Andreas Hepp, Andreas Breiter and Uwe Hasebrink
}

\subsection{Transforming Communications in Times of Deer Mediatization}

Since the early 2000s mediatization has become a new, anchoring concept in media and communication research. In essence, mediatization is a 'sensitising concept' (Blumer 1954: 7), in other words a concept that makes us sensitive to two kinds of empirical phenomena (Jensen 2013: 206-208).

The first of these, called the 'quantitative aspects' of mediatization (Couldry and Hepp 2013: 197), is the spread of technologically based communication media. There is virtually no domain in society today that does not somehow relate to media (Lunt and Livingstone 2016: 464).

\footnotetext{
A. Hepp $(\triangle) \cdot$ A. Breiter

ZeMKI, Centre for Media, Communication and Information

Research, University of Bremen, Bremen, Germany

e-mail: ahepp@uni-bremen.de
}
A. Breiter
e-mail: abreiter@informatik.uni-bremen.de
U. Hasebrink

Hans Bredow Institute for Media Research, University of Hamburg, Hamburg, Germany

e-mail: u.hasebrink@hans-bredow-institut.de

(C) The Author(s) 2018

A. Hepp et al. (eds.), Communicative Figurations,

Transforming Communications - Studies in Cross-Media Research, https://doi.org/10.1007/978-3-319-65584-0_1 
If we reflect on how we maintain our family relationships, friendships and relationships with our colleagues, how learning, work and leisure, how politics, regulation and administration take place, everything is done nowadays with the use and help of technologically based communication media. As a consequence of this spread of media across all domains of society, it would be inappropriate to continue to understand 'media' as a separate sphere of society (Livingstone 2009: 2f.).

Second are the related 'qualitative aspects' of mediatization (Couldry and Hepp 2013: 197), whereby this spread of technical communication media makes a difference to how social reality is constructed. Irrespective of the social domains that we are talking about, their social construction changes when it takes place with the help of media. We maintain our relationships differently via the use of media (Madianou and Miller 2012), just as we construct other domains of society differently when helped by media. This has to do with the particularities and specificities of media; that is, how they change the possibilities of communication (cf. Lundby 2014). For example, media make it possible to extend processes of social construction locally. Moreover, they offer new chances to stabilize processes or bring in new dynamics by speeding up communication. This is what is called the 'shaping role' or 'moulding force' of media within processes of social construction (Hepp 2013: 54).

Such changes are not merely to do with the media as such but about how communication transforms thanks to changing media. It is through changes in human communicative practices together with other social practices that social construction processes change. This is what we call transforming communications. Understood in this way, analyzing transforming communications is not a question of media effects; rather it has to do with analyzing a dialectic relation: media shape or mould practices of communication. We communicate differently depending on the media we use because these media differ in their affordances and specificities (Hjarvard 2013: 27-30). At the same time, media come into existence by building up means and infrastructures of enabling and enhancing communication (Hepp 2013: 54-68). From this point of view, media are institutionalizations and materializations of practices of communication. So, while shaping communication when being established, media at the same time are rooted in the social necessity of communication. We are not confronted with a one-way street of media-driven changes but with a complex dialectic in which social construction becomes more and more entangled with media. This dialectic is the starting point for this volume.

However, we must be aware that mediatization has fundamentally changed over the last decades. For a long time, mediatization research 
had two waves of mediatization in focus: mechanization and electrification. Neither of these relates to the emergence of one single medium but to the qualitative change of the whole media environment. When media became mechanical-a change that is mostly related to the printing press-a 'systematic cultural transformation began to take hold' (Thompson 1995: 46). As John B. Thomson put it in his book on the emergence of modern societies and their relationship with technically based communication media, the mechanization of communication media offered the chance that 'symbolic forms [could be] produced, reproduced, and circulated on a scale that was unprecedented' and 'patterns of communication and interaction began to change in profound and irreversible ways' (Thompson 1995: 46). The institutional basis for this was the development of media organizations as they first appeared in the second half of the fifteenth century. This process intensified with the use of electricity, that is when radio and television developed and when the various mechanical media of print became dependent upon electricity. Especially because of electronic media such as television, the idea of a 'media logic' crystallized, that is the assumption of a unifying logic of certain media (Altheide and Snow 1979; Asp 1990; Schulz 2004; Mazzoleni 2008; Lundby 2009).

But owing to digitalization we are now confronted with a new wave of mediatization (Finnemann 2011, 2014). Again, the significance of this is not the mere invention of a new medium but the qualitative change occurring in the whole media environment: 'New' digital media arose; and the 'old' mechanical and electronic media also became digital. This is, for example, the case for television, which nowadays is digitally produced, transmitted and watched (using digital television sets, tablets or other devices). In addition, the originally mechanically produced book and newspaper were produced digitally, and later on used as digital artefacts (Thompson 2005). This relates to a remarkable shift to 'datafication' (van Dijck 2014): media are not only means of technologically based communication any more. Being digital, at the same time and in addition they became means of producing data that can be delinked from the specific acts of communication and can be used for very different purposes. For example, communicating online via digital platforms, we produce 'metadata' of our social networks, and searching or buying online we leave 'digital traces' (Karanasios et al. 2013: 2452). Such data is processed by algorithms in automatized ways. Processes of social construction through media no longer refer only to human communication, but also to the 
automatized accumulation and calculation of the data we produce while we use digital devices for communication. Or to put it differently, the social world becomes more and more constructed through datafication.

We can understand this as a new stage of mediatization which needs a distinct term to reflect its specificity. We want to call this new stage one of deep mediatization (cf. Couldry and Hepp 2017: 7; Hepp and Hasebrink in this volume). Deep, at this point, has at least a double meaning. First, through the advanced spread of media by digitalization, the character of the social world we inhabit very deeply relies on these technologically based communication media. Second, being digital, these media are not only means of social construction through communication but in addition and on a 'deeper' level means of construction through datafication. With deep mediatization, the very elements and building blocks from which a sense of the social is constructed become themselves based on technologically based processes of mediation. In such a sense, deep mediatization is an advanced stage of mediatization. This results in new challenges for research-such as how we can properly analyze transforming communications in times of deep mediatization.

\subsection{Taking a Figurational Approach}

The origin of this volume is research that is being undertaken in a Creative Research Unit funded by the German Excellence Initiative in order to develop a new approach to research on transforming communications in times of deep mediatization. ${ }^{1}$ One important implication of deep mediatization is that research has to take on a cross-media perspective. As already pointed out, the different waves of mediatization do not refer to the emergence of one single kind of new medium which can be analyzed in an isolated way but to changes in the whole media environment. This implies that research has to look at a variety of different media and take their interrelations into account. Taking an actor's point of view - that is, the perspective of humans acting in this changing media environment - there are even more arguments for this cross-media perspective. In times of deep mediatization, what matters is not the way humans act in social domains in respect of any one single medium, but the way in which a whole variety of different media figure in constructing these different social domains. To give some examples. We inform ourselves via online news, news apps, television and weekly papers (Hasebrink and Domeyer 2010). Our learning does not refer to one 
single kind of medium (i.e. the book), but to a wide variety of different media (Livingstone and Sefton-Green 2016: 107-147). And our work practices exist across a variety of different media as work more and more becomes 'digital labour' (Scholz 2013: 1). Therefore, from the point of view of everyday practice, we have to take this 'polymedia' (Madianou and Miller 2013) or 'transmedia' (Jansson and Lindell 2014) of present processes of communication seriously. However, doing this implies that we can no longer build our analysis around the investigation of any one kind of medium that is considered as having an impact. Instead, a change of perspective towards a cross-media approach is called for; one that analyses how the various media come together in the communicative construction of social domains. Or put differently, the question is how transforming communications takes place across media in each of these domains.

In doing so, it is obvious that a new analytical concept becomes necessary, one which is able to offer the basis for cross-media research on transforming communications. The idea of the Creative Research Unit was to bring researchers from various disciplines together in order to develop this analytical concept jointly. To reflect the technical nature of deep mediatization from various perspectives, besides scholars from media and communication studies, the Creative Research Unit involved researchers from cultural history, informatics, educational sciences, the study of religion as well as sociology and political science. By comparing transforming communications in various social domains, we developed an approach for describing the communicative and therefore social construction as being rooted in various 'communicative figurations' (Hepp and Hasebrink 2014; Hepp and Hasebrink in this volume). The term figuration goes back to Norbert Elias (1978), who used it to describe structured interrelations between humans in situations such as for example families, groups of office colleagues or political parties. The special capacity of Elias's original idea was his consideration that figurations are not 'given' but are (re)produced in an ongoing 'doing'. In this, Elias's idea has a certain closeness to practice theory in its present form (Couldry 2004; Pentzold 2015).

For the analysis in question, we also had to sharpen and extend the original concept when it comes to questions of communication. This is the reason why we speak of communicative figurations. We sharpened it by distinguishing three features of communicative figurations (see Hepp and Hasebrink in this volume): first the constellation of actors who arehaving characteristic social roles-involved in a figuration. The second 
feature constitutes the shared orientations that these actors have in practice within a figuration; that is, their frames of relevance. And the third feature comprises the practices of communication by which these figurations are constructed as meaningful. At the same time, we had to extend the idea of figurations compared with the original idea conceived by Elias, who did not further reflect on the role that technologically based communication media play in our present social world of deep mediatization. Therefore, communicative figurations, as we use this term, are fundamentally entangled with the characteristic media ensemble that the communicative practices refer to.

The core idea of our Creative Research Unit was to develop this figurational approach theoretically on the basis of and in close relation to empirical research. To do this practically, the Creative Unit was structured in three groups, each consisting of a number of projects: one group focusing on individuals, their habits, learning and everyday coping in a changing media environment; one group focusing on social relation by researching localities and social movements, identity constructions and communication networks; and one group dedicated to social fields, namely those of economics, religion, education and politics.

To hold this research together and to ensure theoretical discussion and reflection across the different projects, we met regularly to discuss the progressing empirical work. The Creative Unit also held various workshops and conferences, partly in cooperation with other institutions and associations. Topics covered were approaches to investigating media-related changes, rethinking the mediatization of politics (in cooperation with the Section Mediatization of the European Communication Research and Education Association, ECREA), the expertization of amateurs, diversity in inter- and transcultural communication (in cooperation with the International Communication Section of the German Communication Association, DGPuK), a workshop on media, the city and mobility, a workshop on mediatization and social movements (in cooperation with the Media Sociology Section of the German Communication Association, DGPuK) and finally a concluding conference at which the results published in this book were presented and discussed.

All this was done in close cooperation with colleagues at the HansBredow-Institute Hamburg as well as the University of Hamburg, who are part of our Communicative Figurations network. The idea is to continue its work after this Creative Research Unit ceases its activities. As a research network, we hope to be able to provide a basis for cooperative 
research on transforming communications in times of deep mediatization and to stimulate others who are developing more complex, multi-level approaches to understanding media-related changes in the social world.

\subsection{An Overview of This Volume}

This volume is structured in four parts. The first part acts as an introduction, the second is dedicated to collectivities and movements, the third to institutions and organizations, and the fourth to methodologies and perspectives of research.

Part I: Introduction consists-besides this introductory chapter-of a chapter by Andreas Hepp and Uwe Hasebrink in which they outline a figurational approach to investigate transforming communications. This chapter explains the concept of deep mediatization, discusses the trends of the present changing media environment and explains our approach to communicative figurations. As this is the underlying concept for all other chapters in this volume, the chapter by Hasebrink and Hepp is an important step for our overall line of thought.

Within Part II: Collectivities and Movements the figurations of different collectives are analyzed. The first chapter investigates the complexity of young people's urban communities in the mediatized city. In doing so, Andreas Hepp, Piet Simon and Monika Sowinska have a double focus. On the one hand, they analyze young people's friendship groups. On the other hand, they explore the figurative quality of mediatized locations in the city; that is, how far certain locations support specific methods of community building. The following two chapters focus on the figurations of different social movements. Sebastian Kubitschko analyzes the communicative construction of media technology as a political category within the Chaos Computer Club. He is interested in the (historical) formation of this critical hacker association in Germany and how acting on media technologies and infrastructures becomes a core issue. In her chapter, Sigrid Kannengießer investigates the consumption-critical media practices of the repair café movement. She is especially interested in the specific actor constellations of repair cafés and in the formation of communicative communities in and through repair cafés. The chapter by Karsten Wolf and Urszula Wudarski reflects the expertization within two cultures of amateur learning: do-it-yourself maker and multi-player online gaming. Taking these two cases, the chapter explores how recent technological changes support new forms of amateur learning and expertization. Taking 
a historical point of view, Yvonne Robel and Inge Marszolek discuss the construction of space-related identities in Hamburg and Leipzig. They can demonstrate the importance of local and global spaces in the construction of imagined identities with relation to these cities. And in the last chapter of Part II, through a network analysis Thomas Friemel and Matthias Bixler approach what they call networked media collectivities: collectivities of adolescents as they are constructed by a joint interest in and by the use of media as contents and technologies. In all, Part II of this volume addresses different figurations of collectivity building, their specificities and transformation in times of deep mediatization.

The following Part III: Institutions and Organizations changes the perspective: less informal collectivities and their transformations are of interest but primarily the focus is on formalized institutions and organizations. In the first chapter, Leif Kramp and Wiebke Loosen reflect on the transformation of journalism. Based on various empirical studies, they investigate to what extent newsroom cultures and the communicative orientation of journalists to their audience change. Rebecca Venema and Stefanie Averbeck-Lietz move to another organizational context, that of professional online blogging, and look at the so-called financial crisis in 2008. They ask to what extent financial blogging was a moralizing or a deliberating venture. The organization of interest in the chapter by Kerstin Radde-Antweiler, Sina Gogolok and Hannah Grünenthal is the Catholic Church. With reference to recent media developments, they ask how the construction of religious authority has changed. A further move in the institutional perspective is undertaken in the chapter by Tanja Pritzlaff-Scheele and Frank Nullmeier. Being interested in political institutions, they reflect the remaining importance of face-to-face interactions in figurations of political decision-making. The last chapter in this section is by Andreas Breiter and Arne Hendrik Schulz. They focus on the school as an organization. Comparing England and Germany, Breiter and Schulz reconstruct the changing role of media in these different figurations and reflect on governance to explain differences between both countries.

Part IV of this volume moves to Methodologies and Perspectives. The first three chapters discuss the extent to which researching communicative figurations in times of deep mediatization needs new methodological approaches and methods. Taking a more general point of view, Christine Lohmeier reflects on the methodological challenges of researching communicative figurations. Mainly, she argues that they are rooted in the related move to a non-mediacentric and at the same time cross-media 
perspective. More specific problems for the methods are addressed in the following two chapters. On the basis of various tests, Juliane Klein, Michael Walter and Uwe Schimank ask what kinds of qualitative interview strategies are appropriate for the investigation of individuals' media repertoires and their relation to certain figurations. The interest of Andreas Breiter and Andreas Hepp in their chapter is the technological side of deep mediatization. They discuss the challenge of putting digital traces in context by the triangulation of automatized data analysis with qualitative data. The following two chapters are written by authors who are not part of the Communicative Figurations research network, and therefore they offer an external perspective on the possibilities of this approach. Kim Schrøder takes a methodological point of view and asks about the implications in this respect. And finally, Giselinde Kuipers reflects the theoretical perspectives of such an approach.

In all, the chapters of this volume cannot and are not aimed at offering a final analysis of transforming communications. This is a project which needs much more effort and a much longer perspective than is possible in a three-year Creative Research Unit. Rather, the idea is that the chapters demonstrate how far a figurational approach is able to link empirical research into transforming communications in various areas in a way that comparison across them becomes possible. It is exactly this kind of comparative research that is needed if we want to understand the changes in our social world that are driven by the trends of deep mediatization in a changing media environment. Our hope is that this volume is able to inspire future research with such a perspective.

\section{Note}

1. Creative Units are a format in the institutional strategy of the University of Bremen to offer a kind of exploratory funding to research emergent and new areas. Support for these Creative Units is based on the additional research funding accruing to the University of Bremen as a University of Excellence.

\section{REFERENCES}

Altheide, David L., and Robert P. Snow. 1979. Media logic. Beverly Hills, CA: Sage. Asp, Kent. 1990. Medialization, media logic and mediarchy. Nordicom Review $11(2): 47-50$. 
Blumer, Herbert. 1954. What is wrong with social theory? American Sociological Review 19: 3-10.

Couldry, Nick. 2004. Theorising media as practice. Social Semiotics 14 (2): $115-132$.

Couldry, Nick, and Andreas Hepp. 2013. Conceptualising mediatization: Contexts, traditions, arguments. Communication Theory 23 (3): 191-202.

Couldry, Nick, and Andreas Hepp. 2017. The mediated construction of reality. Cambridge: Polity Press.

Elias, Norbert. 1978. What is sociology? London: Hutchinson.

Finnemann, Niels O. 2011. Mediatization theory and digital media. European Journal of Communication 36 (1): 67-89.

Finnemann, Niels O. 2014. Digitalization: New trajectories of mediatization? In Mediatization of communication, ed. Knut Lundby, 297-322. Berlin, New York: de Gruyter.

Hasebrink, Uwe, and Hanna Domeyer. 2010. Zum Wandel von Informationsrepertoires in konvergierenden Medienumgebungen. In Die Mediatisierung der Alltagswelt, ed. Maren Hartmann and Andreas Hepp, 49-64. Wiesbaden: VS.

Hepp, Andreas. 2013. Cultures of mediatization. Cambridge: Polity Press.

Hepp, Andreas, and Uwe Hasebrink. 2014. Human interaction and communicative figurations: The transformation of mediatized cultures and societies. In Mediatization of communication, ed. Knut Lundby, 249-272. Berlin, New York: de Gruyter.

Hjarvard, Stig. 2013. The mediatization of culture and society. London: Routledge.

Jansson, A., and J. Lindell. 2014. News media consumption in the transmedia age: Amalgamations, orientations and geo-social structuration. Journalism Studies 16 (1): 79-96.

Jensen, K.B. 2013. Definitive and sensitizing conceptualizations of mediatization. Communication Theory 23 (3): 203-222.

Karanasios, Stan, Dhavalkumar Thakker, Lydia Lau, David Allen, Vania Dimitrova, and Alistair Norman. 2013. Making sense of digital traces: An activity theory driven ontological approach. Journal of the American Society for Information Science and Technology 64 (12): 2452-2467.

Livingstone, Sonia, and Julian Sefton-Green. 2016. The class. living and learning in the digital age. New York: NYU Press.

Livingstone, Sonia M. 2009. On the mediation of everything. Journal of Communication 59 (1): 1-18.

Lundby, Knut. 2009. Media logic: Looking for social interaction. In Mediatization: Concept, changes, consequences, ed. Knut Lundby, 101-119. New York: Peter Lang.

Lundby, Knut. 2014. Mediatization of communication. In Mediatization of communication, ed. Knut Lundby, 3-35. Berlin, New York: de Gruyter. 
Lunt, Peter, and Sonia Livingstone. 2016. Is 'mediatization' the new paradigm for our field? A commentary on Deacon and Stanyer $(2014,2015)$ and Hepp, Harvard, and Lundby (2015). Media, Culture and Society 38 (3): 462-470.

Madianou, Mirca, and Daniel Miller. 2012. Migration and new media: Transnational families and polymedia, lst ed. London: Routledge.

Madianou, Mirca, and Daniel Miller. 2013. Polymedia: Towards a new theory of digital media in interpersonal communication. International Journal of Cultural Studies 16 (6): 169-187. doi:10.1177/1367877912452486.

Mazzoleni, Gianpietro. 2008. Mediatization of society. In The international encyclopedia of communication, vol. VII, ed. Wolfgang Donsbach, 3052-3055. Oxford: Blackwell Publishing.

Pentzold, Christian. 2015. Praxistheoretische Prinzipien, Traditionen und Perspektiven kulturalistischer Kommunikations- und Medienforschung. Medien \& Kommunikationswissenschaft 63 (2): 229-245.

Scholz, Trebor. 2013. Introduction: Why does digital labour matter now? In Digital labor. The internet as playground and factory, ed. Trebor Scholz, 1-9. New York: Routledge.

Schulz, Winfried. 2004. Reconstructing mediatization as an analytical concept. European Journal of Communication 19 (1): 87-101.

Thompson, John B. 1995. The media and modernity. A social theory of the media. Cambridge: Cambridge University Press.

Thompson, John B. 2005. Books in the digital age. Cambridge, Malden: Polity. van Dijck, José. 2014. Datafication, dataism and dataveillance: Big Data between scientific paradigm and ideology. Surveillance and Society 12 (2): 197-208.

Open Access This chapter is licensed under the terms of the Creative Commons Attribution 4.0 International License (http://creativecommons.org/licenses/ by $/ 4.0 /$ ), which permits use, sharing, adaptation, distribution and reproduction in any medium or format, as long as you give appropriate credit to the original author(s) and the source, provide a link to the Creative Commons license and indicate if changes were made.

The images or other third party material in this chapter are included in the chapter's Creative Commons license, unless indicated otherwise in a credit line to the material. If material is not included in the chapter's Creative Commons license and your intended use is not permitted by statutory regulation or exceeds the permitted use, you will need to obtain permission directly from the copyright holder.

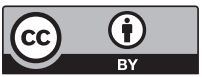

